\title{
System analysis of power consumption by non- ferrous metallurgy enterprises on the basis of rank modeling of individual technocenosis castes
}

\author{
Roman V. Klyuev*, Igor I. Bosikov, Oksana A. Gavrina, and Vladimir Ch. Revazov \\ North Caucasian Institute of Mining and Metallurgy (State Technological University), Industrial \\ Power Supply Department, 44 str. Nikolaeva, Russia
}

\begin{abstract}
To increase energy efficiency at non-ferrous metallurgy enterprises, an integrated system approach for estimation of electricity consumption is needed. The paper presents the results of a rank analysis of the power consumption of individual castes of process equipment on the basis of an integrated energy survey of the enterprise. A methodology for constructing mathematical models for calculating and predicting electric power consumption for all castes of the ranked H-distribution of technocenosis has been developed. For the first time, according to the established regularity of the H-distribution, a mathematical model for predicting power consumption has been developed, including a quantitative analysis of the energy characteristics of consumers by individual castes of technocenosis. A retrospective check of the relative error in the prediction of electricity consumption showed that for the model it does not exceed $2 \%$, which is significantly lower than the relative error of the prediction for a number of models of other types. The received model is recommended for use in the automated system of dispatching control of power consumption for the purposes of short-term forecasting of electric power consumption at industrial enterprises of non-ferrous metallurgy.
\end{abstract}

\section{Relevance of work}

To assess the power consumption in various industries, a systemic technocenosis approach has recently been applied [1-5]. This approach is based on the concept of a technocenosis, which reflects the specificity of the links between technical elements - individuals. It can be considered proven that technical systems, such as large industrial enterprises, live and develop according to the same laws as biological systems (biogeocenoses).

To describe the structure of technocenoses and to identify their development and change trends, a special mathematical apparatus for hyperbolic $H$-distributions that has the form y $y=a / r^{\beta}$ has been developed. Hyperbolic rank $H$-distributions are a decreasing sequence of

\footnotetext{
* Corresponding author: kluev-roman@rambler.ru
} 
parameter values, arranged in such a way that, with increasing rank (ordinal number), each successive number is smaller than the previous one.

A great contribution to the development of the method of the rank H-distribution for calculation of electrical loads has been made by Kudrin B.I. [1, 2], Fufaev V.V. [3], Gnatiuk V.I., Isaev A.S., Lagutkin O.E., Orlov Yu.K., Oshurkov M.G.

\section{Scientific novelty, statement of the problem, research methods}

A method was developed for the rank analysis of individual castes of the technocenosis of non-ferrous metallurgy enterprises, which makes a significant scientific contribution to the mathematical modeling and forecasting of electricity consumption under the management of the system.

The most important task of the rank analysis should be considered a comprehensive study of the structure and technological processes of the main energy-intensive consumers, which have the greatest impact on the specific consumption of electricity and energy saving in the production of non-ferrous metals.

The main stages of rank analysis are the following:

- the separation of technocenosis (a non-ferrous metallurgy enterprise);

- definition of the list of types (consumers of electricity);

- specification of type-forming parameters;

- a parametric description of the technocenosis (castes);

- construction of tabulated and graphical rank parametric distributions;

- approximation of distributions;

- optimization of technocenosis.

The solution of the set problems is based on the system approach that includes instrumental and analytical research methods, rank distribution, mathematical modeling and energy audit.

\section{Theoretical part}

At the stage of statistical analysis and construction of an empirical model of the power consumption process, a full-scale statistical processing of data on power consumption is carried out, which includes rank analysis. Rank analysis makes it possible to organize information, effectively perform forecasting of power consumption by individual objects and the enterprise as a whole, and identify in dynamics and visualize objects with abnormal power consumption $[4,5]$.

The rank analysis consists in breaking up the technocenosis objects into three groups of ranks: noah, pointer, and locust distribution castes. Noah caste is a group of the most energy-intensive objects occupying the first ranks of the rank $H$-distribution and forming the first point of the approximating rank $H$-distribution. Pointer-caste is a group of objects connected by a function of price influence, a row of which determines the numerical value of the rank index $\beta$. The locust caste (virtual) is a group of objects located beyond the pointer boundary. This is a group of small objects corresponding to large ranks (the "long tail" of the rank H-distribution) and practically indistinguishable in terms of the parameter.

For the nonferrous metallurgy enterprise of Russia OJSC "Pobedit", which is one of the largest nonferrous metallurgy enterprises in the Russian Federation for the production of hard alloys, an energy audit was conducted. Energy-intensive production, the presence of a large number of consumers of different capacities and operating modes of consumers predetermines OJSC "Pobedit" as a worthy object for conducting a serious energy audit at a high level. 
During the energy audit it was established that the most energy-intensive equipment of the plant are electrolyzers, welding machines and pumps. They account for about $47 \%$ of the total power consumption of the enterprise.

Figure 1 shows the graphs of the electricity consumption of the enterprise for the period from 2006 to 2017.

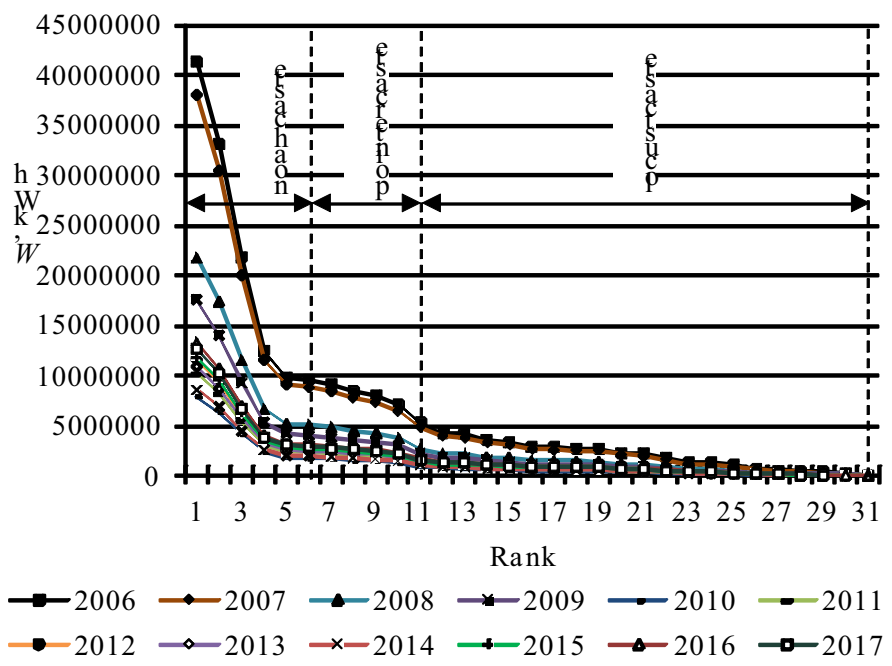

Fig. 1. Schedule of power consumption of OJSC "Pobedit" for the period of 2006-2017.

Based on the results of the construction of successive rank $H$-distributions, the most energy-intensive equipment is referred to the noah distribution caste (consumers with a rank of 1-6).

Similarly, the equipment constituting the pointer and the locust distribution caste (consumers with grades 7-11 and 12-31-respectively) is defined.

The following algorithm for determining the confidence intervals of the power consumption of the process equipment of individual distribution caches was developed:

1. According to the power counters, output $\{W\}$ of energy values of volume $n$ over a time period $t$ is formed.

2. The mean and standard output are calculated $\{W\}$.

3. The anomalous values of power consumption, which go beyond the limits of confidence intervals, which are excluded from output $n$, refine the truncated output of power consumption values of volume $n_{1} \leq n$ are determined.

4. The upper and lower limits of the confidence interval are calculated.

5. The adequate mathematical model of electricity consumption, which is an exponential-damped harmonic function, is composed in the following form:

$$
W(t, u)=\cos \left(u_{0} t+u_{1}\right) \mathrm{e}^{u 2 t}+u_{3}
$$

where $t$ is time, year; $u_{0}, u_{1}, u_{2}, u_{3}$ are constant coefficients for the determination of which a matrix is formed, the first element of which is the initial function, the rest are the partial derivatives of the determined coefficients.

Analysis of equation (1) shows that when the actual values of energy consumption are selected for 5 or more years, the predicted value $\approx u_{3}$ (does not depend on time).

6. For a short-term forecast of the magnitude of electricity consumption with a lag of 1 year, the mathematical model (1) is used in which the forecast time period is $t+1$. 
7. The retrospective assessment of the relative error of the model is conducted. As compared values are taken to be actual electricity consumption and forecasted energy received from a mathematical model.

Thus, according to the proposed algorithm, the following mathematical model is obtained for the largest consumer of the noah caste of the electrolysis distribution: $W=\cos (-1.067 t+0.338) \mathrm{e}^{-0.515 t}+1.236$; the coefficient of determination is 0.726 . The forecast error was: $1.34 \%$.

Figure 2 shows the corresponding graphs of power consumption and the approximating dependences of the technological equipment of the noah caste of distribution, obtained using the method of least squares.

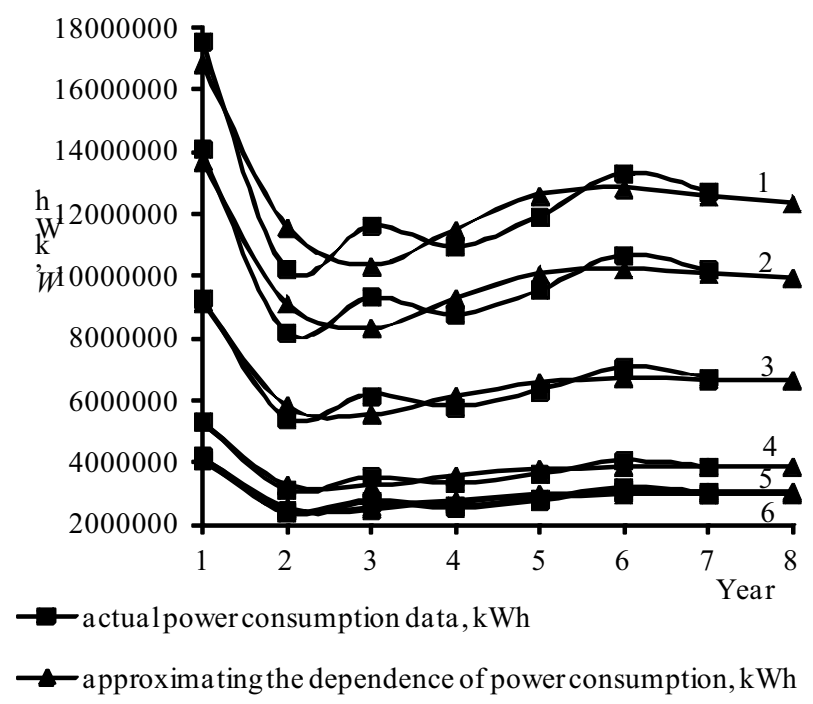

Fig. 2. Graph of power consumption of the noah caste consumers and approximating dependencies.

The results of the rank analysis of electricity consumption have shown the stability and efficiency of the H-distribution with reference to the technological equipment of the noah caste for the production of non-ferrous metals [6-11].

\section{Conclusion}

1. A methodology has been developed for constructing mathematical models for calculating and predicting electricity consumption for all castes of the rank $\mathrm{H}$-distribution of technocenosis.

2. For the first time, the regularity of the change in electric power consumption by technological equipment is defined, which is described by an adequate mathematical model in the form of a damped harmonic function (1).

3. Retrospective verification of the relative error in the forecasting of electricity consumption showed that, for the obtained model $W(t, u)$ it does not exceed $2 \%$, which is much lower than the relative prediction error of a number of models of other types. The received model is recommended for use in the automated system of dispatching control of power consumption for the purposes of short-term forecasting of electricity consumption in industrial enterprises. 
The results were reflected in the Grant of the President of the Russian Federation for support of young scientists: MK-1324.2007.8 on "Research and development of mathematical models of power quality in the non-ferrous metallurgy enterprises".

\section{References}

1. B.I. Kudrin, B.V. Zhilin, O.E. Lagutkin, Cenological definition of the parameters of power consumption of multinomenclature industries (Priokskoe Publishing House, Tula, 1994)

2. B.I. Kudrin, Philosophy of technology: classical, postclassical, post-non-classical (Technika, Moskow, 2008)

3. V.V. Fufaev, Cenological definition of the parameters of power consumption, reliability, installation and repair of electrical equipment in the region (Center for System Studies, Moskow, 2000)

4. R V. Klyuev, I. I. Bosikov, 2nd International Conference on Industrial Engineering, Applications and Manufacturing (ICIEAM), 1-5 (2016)

5. R. B. Youn, R. V. Klyuev, I. I. Bosikov, B. V. Dzeranov, Sustainable Development of Mountain Territories, 9 2(32) 172 (2017)

6. M. Choobineh, S. Mohagheghi, IEEE Transactions on Industry Applications, 52 I.3, 1945 (2016)

7. B. Jovanović, J. Filipović, V. Bakić, Journal of Cleaner Production, 162, 1144 (2017)

8. D. Lee, C.-C. Cheng, Renewable and Sustainable Energy Reviews, 56, 760 (2016)

9. M. Glavic, R. Fonteneau, D, Ernst, IFAC-PapersOnLine, 50, 6918 (2017)

10. L. Fiaschetti, M. Antunez, E. Trapani, L. Valenzuela, International Journal of Electrical Power \& Energy Systems, 94, 67 (2018)

11. K. M. Muttaqi, J. Aghaei, V. Ganapathy, A. E. Nezhad, Renewable and Sustainable Energy Reviews, 46, 129 (2015) 